\title{
Management of feverish children at home
}

\author{
Ann-Louise Kinmonth, Yvonne Fulton, M J Campbell
}

Primary Medical Care, University of

Southampton, Aldermoor Health Centre,

Southampton SO1 6ST

Ann-Louise Kinmonth, professor

College of Nursing, Southampton General Hospital, Southampton

Yvonne Fulton, nurse tutor in paediatrics

Medical Statistics and Computing, University of Southampton,

Southampton General Hospital, Southampton

M J Campbell, senior lecturer

in medical statistics

Correspondence and requests for reprints to: Professor Kinmonth.

$B M F$ 1992;305:1134-6
Abstract

Objectives-To compare the acceptability and effects on temperature of advice to unwrap children and give paracetamol or warm sponging treatments in the management of feverish illness at home.

Design-A randomised, open, parallel group study using factorial design comparison of unwrapping, warm sponging plus unwrapping, paracetamol plus unwrapping, and paracetamol and warm sponging plus unwrapping.

Setting-Homes of willing families with a feverish child recruited after consulting one of 21 participating general practitioners in Southampton.

Subjects-52 children aged from 3 months to 5 years with axillary temperatures before treatment of $\geqslant 37.8^{\circ} \mathrm{C}$ and $<40^{\circ} \mathrm{C}$.

Main outcome measures-Response to advice assessed over four hours; temperature assessed by continuous data logging from an axillary thermistor; acceptability of treatment to child and parent scored on Likert scales immediately after treatment and on return to health.

Results-Response to treatment advice varied; unwrapping alone had little effect on temperature. Paracetamol increased the time below $37.2^{\circ} \mathrm{C}$ in four hours by 109 (95\% confidence interval 74 to 145) minutes compared with unwrapping; warm sponging caused the fastest reduction in temperature. Parents discriminated between treatments, preferring paracetamol.

Conclusion-Advice to give paracetamol is more effective than sponging or unwrapping in controlling temperature in children at home and is more acceptable to parents. Warm sponging has an additive effect and reduces fever more quickly than paracetamol.

\section{Introduction}

We are taught to treat feverish illness in the young

for an adult to be comfortable naked. Encourage frequent cool drinks.

Warm sponging-In a warm room (as above) sit your child in a bath or bowl containing a few inches of warm water of a temperature just below that of yourd child. Wet the child all over with warm water for 10-20 minutes or as long as the child is comfortable. Do not leave the child unattended. Then unwrap the child $\vec{O}$ (as above).

Paracetamol-Give one or two $5 \mathrm{ml}$ spoonfuls of sugar free paracetamol suspension (Junior Disprol, Reckitt and Colman) (up to 1 year $120 \mathrm{mg}$, over 1 year?. $240 \mathrm{mg}$ ) by spoon or dispensing syringe. Then unwrap the child (as above).

Paracetamol and warm sponging-The advice giveno above was combined.

\section{MEASURES}

Temperatures-Axillary temperature was measuredo at entry into the trial with a digital thermometer (Becton Dickinson) and during the profile with a dataZ logger (Squirrel logger, 1200 series, Grant) and a minithermistor, which recorded temperature averaged 3 over one minute every five minutes. Room and waterס्ष temperatures were recorded by the data logger. $A_{-}^{-}$ 15 minute equilibration period was allowed before the profiles were started.

Acceptability to the child was scored on a 1-4 scale? by observing whether the child enjoyed, didn't mind, did mind, or refused the treatment. Parental satisfaction with treatment was scored on a 1-5 scale (see table II) after the profile and on the child's return to health.

Other measures-A diary was kept of the child'so behaviour throughout the profile. Symptoms and axillary temperature at bedtime were recorded byo parents until the child was well. Clinical characteristics were defined by direct observations or from the patient's notes. Clothes and children were weighed using a portable scale (Krups; weight range 0-150 kilo- 3 grams).

child by treating the underlying cause. ${ }^{1}$ Most children presenting in primary care with moderate fever $\left(<40^{\circ} \mathrm{C}\right)$, however, have self limiting viral infections. ${ }^{2}$ The management of the raised temperature and of the symptoms thus becomes important. This study was designed to compare the acceptability and effects on temperature of the addition of paracetamol or warm sponging to simple unwrapping and encouraging taking cool drinks among feverish children at home.

\section{Methods}

Children were randomised by envelopes within blocks stratified by age to four treatment advice groups within a factorial design. A research nurse studied each child over four hours at home and followed children up until well. Analysis was by intention to treat.

\section{ADVICE TO PARENTS}

The nurse advised parents as follows:

Unwrapping - Unwrap your child into light clothing (vest and nappy, for example) in a room warm enough

\section{RECRUITMENT}

Children aged from 3 months to 5 years (inclusive) presenting to their general practitioner with an axillaryo temperature of $37.8^{\circ} \mathrm{C}$ to $39.9^{\circ} \mathrm{C}$ were recruited by> the doctor and visited by the research nurse, who confirmed eligibility. The study had ethical approvaln and parents willing to join any of the treatment groupsN gave written consent.

Exclusion criteria were an axillary temperature $>40^{\circ} \mathrm{C}$, serious concomitant disease, a history of febrile convulsions, having taken antipyretic drugse in the preceding four hours, contraindications to paracetamol, and inconvenient times (after $6 \mathrm{pm}$ ).

\section{STATISTICS}

Power calculations from a pilot study ${ }^{3}$ estimated that 15 children would be needed in each group for a type error of 0.05 and type 2 error of 0.10 in detecting 20 difference in time below $37.2^{\circ} \mathrm{C}$ of 60 minutes withint four hours between subgroups with and without paracetamol. Analysis of temperature used two summary measures, ${ }^{4}$ and analysis of covariance allowed for initial temperatures. 


\section{Results}

A total of 52 of 122 eligible children referred by 21 general practitioners were recruited. Thirty two mothers were unwilling or unable to take part, eight children refused to have their temperature measured, and 30 children were referred too late in the day. Three children stopped the profiles early; in two the temperature rose to $40^{\circ} \mathrm{C}$ (at two and at three hours), and one was given more paracetamol (at three hours). Their temperatures at , withdrawal were carried forward in the analysis.

Table I describes the children. The groups were well matched except that more girls received paracetamol. The overall duration of symptoms was similar. The mean (SD) duration of fever reported before presentation was one day $(1 \cdot 4)$. The mean duration of symptoms before presentation was three (3.9) days, and the median two (range 0-20) days. Five children had symptoms for over seven days before presentation. These children had multiple previous consultations for "eczema" or "asthma" or otitis media. Their diagnoses at presentation were otitis media (two), pneumonia (two), and possible pertussis (one). The majority of children in each group (38 overall) had diagnoses of non-specific "viral" or "upper respiratory tract" conditions. Twelve children were receiving antibiotics; 45 mothers $(87 \%)$ had given paracetamol to their children in the past.

Response to treatment advice was variable. Children's wrappings were reduced from a median of $225(25-830) \mathrm{g}$ to $85(24-819) \mathrm{g}$. Some parents added wrappings. Mean room temperature was $21 \cdot 3$ $(13 \cdot 8-28 \cdot 6)^{\circ} \mathrm{C}$. Fluid intake was low; on average only $163(0-750) \mathrm{ml}$ over the four hour period; 10 parents offered no drinks at all.

The median duration of warm sponging was nine (1-82) minutes with water of mean initial temperature $37 \cdot 1(32-41 \cdot 9)^{\circ} \mathrm{C}$ and final temperature $34.7(32 \cdot 2-$ $39 \cdot 2)^{\circ} \mathrm{C}$.

Most children (45/52) accepted "unwrapping." All children took the paracetamol dose, 12 (out of 26) objecting somewhat to it. Twelve children objected somewhat to warm sponging. Twelve children seemed to enjoy the warm sponging and eight the paracetamol.

Table II shows that parents discriminated between treatment groups. Treatments including paracetamol were more acceptable.

The figure shows the mean four hour axillary temperature profiles by treatment. Table III shows the mean time below $37 \cdot 2^{\circ} \mathrm{C}$, which was greatest for

TABLE I-Clinical characteristics of children studied

\begin{tabular}{|c|c|c|c|c|c|}
\hline \multirow[b]{2}{*}{ Clinical characteristic } & \multicolumn{4}{|c|}{ Treatment group } & \multirow[b]{2}{*}{$\begin{array}{c}\text { Total } \\
(n=52)\end{array}$} \\
\hline & $\begin{array}{l}\text { Unwrapping } \\
\quad(n=13)\end{array}$ & $\begin{array}{c}\text { Warm } \\
\text { sponging } \\
(n=13)\end{array}$ & $\begin{array}{c}\text { Paracetamol } \\
(n=13)\end{array}$ & $\begin{array}{l}\text { Paracetamol and } \\
\text { warm sponging } \\
(n=13)\end{array}$ & \\
\hline Sex F/M & $3 / 10$ & $3 / 10$ & $8 / 5$ & $7 / 6$ & $21 / 31$ \\
\hline Mean (range) age (months) & $25(5-45)$ & $37(5-65)$ & $34(5-70)$ & $25(6-61)$ & $30(5-70)$ \\
\hline Mean $(\mathrm{SD})$ weight $(\mathrm{kg})$ & $11(3)$ & $14(5)$ & $12(4)$ & $12(3)$ & $12(4)$ \\
\hline $\begin{array}{l}\text { Median (range) duration of symptoms } \\
\text { (days) }\end{array}$ & $10(2-39)$ & $13(7-41)$ & $10(3-21)$ & $13(3-57)$ & $12(2-57)$ \\
\hline Median (range) consultations per year & $8(0-17)$ & $6(1-15)$ & $8(1-27)$ & $5(0-14)$ & $7(0-27)$ \\
\hline Mean (SD) temperature at entry $\left({ }^{\circ} \mathrm{C}\right)$ & $38 \cdot 5(0 \cdot 4)$ & $38 \cdot 4(0 \cdot 4)$ & $38 \cdot 8(0 \cdot 6)$ & $38.5(0 \cdot 6)$ & $38.5(0 \cdot 5)$ \\
\hline
\end{tabular}

TABLE II-Median acceptability scores by parents at the end of the four hour profile and when the child was well again

\begin{tabular}{lcc}
\hline & \multicolumn{2}{c}{ Acceptability } \\
\cline { 2 - 3 } Treatment & At end of profile & When child well again \\
\hline Unwrapping & 3 & 3 \\
Warm sponging & 3 & 3 \\
Paracetamol & 1 & 1 \\
Warm sponging and paracetamol & 2 & 2 \\
$\chi^{2}$ (Kruskal-Wallis, df=3) & 19.2 & $15 \cdot 6$ \\
p Value & $<0.001$ & $<0.001$ \\
\hline
\end{tabular}

$1=$ Very happy, $2=$ happy, $3=$ not sure, $4=$ unhappy, $5=$ very unhappy.

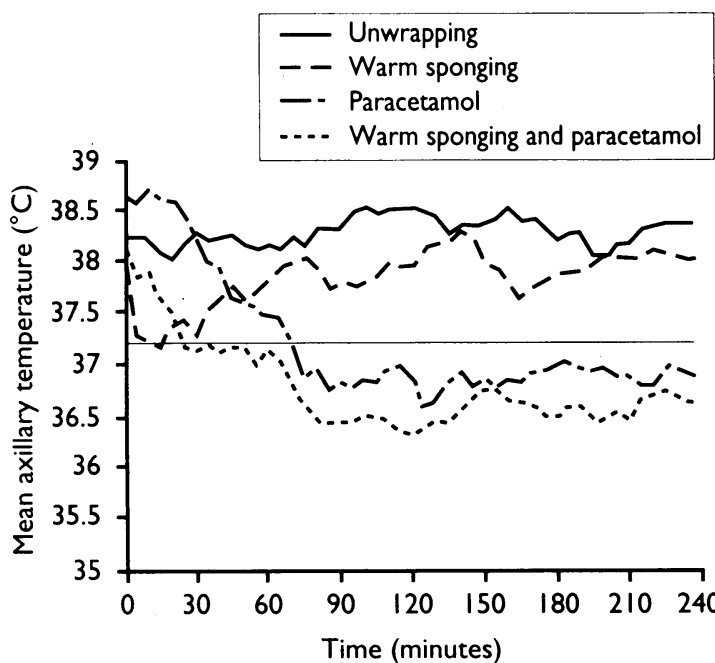

Mean axillary temperature over four hours in 52 feverish children

TABLE III-Mean time below $37 \cdot 2{ }^{\circ} \mathrm{C}$ (minutes) adjusted for initial temperature for the four hour treatment groups in the factorial design (to nearest $0.5 \mathrm{~min}$ )

\begin{tabular}{rlrrr}
\hline & \multicolumn{3}{c}{ Warm sponging $^{\star}$} \\
\cline { 2 - 5 } Paracetamol $\dagger$ & \multicolumn{1}{c}{ No } & \multicolumn{1}{c}{ Yes } & Mean \\
\hline & No & $20 \cdot 5$ & $54 \cdot 0$ & $37 \cdot 0$ \\
Yes & $129 \cdot 0$ & $164 \cdot 0$ & $146 \cdot 5$ \\
Mean & $75 \cdot 0$ & $109 \cdot 0$ &
\end{tabular}

^Effect of warm sponging by analysis of covariance over and above unwrapping $=34(95 \%$ confidence interval $32.5-114) \mathrm{min}$

tEffect of paracetamol over and above unwrapping=109 (74-145) $\mathrm{min}$ Interaction was negligible (2 minutes).

paracetamol and.warm sponging combined. With paracetamol the time below $37 \cdot 2^{\circ} \mathrm{C}$ was more than an hour and a half longer than with unwrapping. The interaction was negligible.

The temperature of seven children (five treated with unwrapping and two with warm sponging) did not fall to $37 \cdot 2^{\circ} \mathrm{C}$ during observation. The mean time to reach $37 \cdot 2^{\circ} \mathrm{C}$ among other children receiving unwrapping alone was 70 minutes, when sponging was added the time was 25 minutes, and when paracetamol was added, 63 minutes. Warm sponging significantly reduced the time taken to reach $37 \cdot 2^{\circ} \mathrm{C}$ compared with unwrapping (31.5 minutes' difference; $95 \%$ confidence interval 7 to 56 minutes), but paracetamol had no significant effect.

Allowing for the covariates age, weight, and maximum and minimum air temperatures and excluding the five children with illness of more than one week before presentation did not affect the results.

\section{Discussion}

This study confirms that giving paracetamol is more effective in controlling childhood fever than using physical methods alone and is acceptable to both children and parents as a home treatment. Antipyretic analgesia seems to be used in the management of up to $90 \%$ of childhood illnesses, ${ }^{5}$ being given on more than $12 \%$ of all days in one survey, ${ }^{6}$ and most mothers in this study had used it among their children. Previou studies of treating fever took place in hospital among children with high fevers $\left(\geqslant 39^{\circ} \mathrm{C} \text { rectal }\right)^{7-9}$ and were designed to be explanatory. ${ }^{10}$ Our study provides information about home management of moderately feverish children in response to standard advice.

Parents' interpretation of the advice was extremely variable: some added wrappings and some used cold or very hot water. Most parents, however, unwrapped their children to vest and pants and sponged with warm water about $1^{\circ} \mathrm{C}$ lower than the temperature of their 
child. This contrasts with previous work using cold water, which often caused distress among the children. ${ }^{7-9}$ Warm sponging was enjoyed by almost half the children studied and was more effective than paracetamol in reducing fever quickly. Parents, however, were happiest with treatments that included paracetamol.

Overwrapping has been popularly held responsible for mild rises in temperature in children, ${ }^{11}$ but we found no evidence to support this. Despite advice to the contrary, the children drank little, and 10 parents offered no fluids at all over four hours. More attention to this part of nursing care might improve wellbeing.

The children in this study were selected by parental consent and availability. They seem, however, to represent the group whose parents consult for advice within two days of illness and have an annual consultation rate somewhat higher than the average 4.9 consultations a year. ${ }^{12}$ The clinical presentations are also typical of those respiratory and non-specific presentations which make up the major consulting workload with under $5 \mathrm{~s}$ in general practice. ${ }^{121}$ Exclusion of children who had had symptoms for more than a week before presentation did not modify our results.

The median duration of illness in all groups was similar, but this study did not have the power to see whether reduction of temperature could result in overwhelming infection in rare cases, or if use of paracetamol might prolong illness. It is reassuring that in a larger randomised control trial the duration of symptoms was similar in children given paracetamol or placebo. ${ }^{14}$

The rationale for treating a raised temperature is to reduce associated discomfort from symptoms or harm from convulsions. ${ }^{15}$ The specific effects of paracetamo on wellbeing remain unclear. ${ }^{14}$ This study describes the variability of response to advice about home management of fever in childhood. It confirms that giving paracetamol is more effective in temperature control than are physical treatments; advice to give paracetamol is broadly acceptable to parents and children. The study also shows the additive effect of warm sponging in reducing fever quickly and draws attention to the low fluid intake among sick children nursed at home.

We thank the families who took part, their general practitioners, and Jean Gibson for typing the paper. We gratefully acknowledge the support of Reckitt and Colman, Becton Dickinson, and the Claire Wand Fund. The protocol was written while Dr Kinmonth was receiving an MRC training grant at the London School of Hygiene and Tropical Medicine.

1 Illingworth RS. Fever. In: The treatment of the child at home: a guide for family doctors. Oxford: Blackwell Scientific, 1971:171.

2 Soman M. Characteristics and management of febrile young children seen in a university family pracice 9 Fam Pract 1985;21:117-22.

3 Ayres R. A more rational approach to the management of feverish children at $\vec{O}$ home [dissertation]. Southampton: University of Southampton, 1986.

4 Matthews JNS, Altman DG, Campbell MJ, Royston JP. Analysis of serial $\overrightarrow{\vec{\omega}}$ measurements in medical research. $B M Y$ 1990;300:230-5.

5 Taylor JP, Gustafson TL, Johnson CC, Brandenburg N, Glezen WP. Antipyretic use among children during the 1983 influenza season. $A m f D i s$ Child 1985;139:486-8

6 Rylance GW, Woods CG, Cullen RE, Rylance ME. Use of drugs by children. $B M F$ 1988;297:445-7.

7 Hunter J. Study of antipyretic therapy in current use. Arch Dis Child 1973;48:313-5

8 Newman J. Evaluation of sponging to reduce body temperature in febrile children. Can Med Assoc $\mathcal{F}$ 1985;132:641-2.

9 Steele RW, Tanaka PT, Lara RP, Bass JW. Evaluation of sponging and of oral antipyretic therapy to reduce fever $\mathcal{I}$ Pediatrics 1970;77:824-9.

10 Schwartz D, Lellouch J. Explanatory and pragmatic attitudes in therapeutic trials. F Chronic Dis 1967;20:637-48.

11 Pantell RH, Naber M, Lamar R, Dias JK. Fever in the first six months of life. Clinical Pediatrics 1980;19:77-82.

12 Royal College of General Practitioners, Office of Population Censuses and $Z$ Surveys, Department of Health and Social Security. Morbidity statistics from general practice 1981-2. London: HMSO, 1986.

13 Bain J. Ear, nose and throat disorders in children: presentation and management in general practice [dissertation]. Aberdeen: University of Aberdeen, 1986

14 Kramer MS, Naimaik LE, Roberts Brauer R, McDougall A, Leduc DG. Risks and benefits of paracetamol antipyresis in young children with fever of 6 presumed viral origin. Lancet 1991;337:591-4.

15 Kluger MJ. Fever Pediatrics 1980;66:720-4.

(Accepted 8 September 1992)

\section{ONE HUNDRED YEARS AGO}

THE FIVE YEARS' CURRICULUM

On the 1st of January in this present year the five years' curriculum became an accomplished fact, and those who enter upon their studies on the 1st of October, if they do not know it already, will be eager to learn in what way it will affect their future career. In reality, the change is not so great as it at first sight appears to be. Many students, especially those who have been working for the higher examinations, have for some years past voluntarily submitted themselves to a period of study longer than the prescribed minimum, and the rejections of the licensing bodies have enforced a lengthened period of study on many others. Nor are future requirements very largely in excess of the past. A little extra preliminary biology to start with, and an increased knowledge of the specialities to end up with, sum up the principal additions to the educational bill of fare. In the case of the higher or University examinations, the change is practically one of time only. But with this lengthening of time comes an important concession to the student. His last year may be spent in one of two ways; either entirely at a medical school, or half of it may be spent at certain recognised places of study, amongst which are included specia hospitals and workhouse infirmaries, and the remaining six months devoted to work at a medical school.

The question at issue thus narrows itself into a consideration of the extra work and increased examinations which are demanded by the licensing corporations, which, excepting in the case of the Conjoint Board for England, which has instituted an extra clinical examination, may, as we have already stated, be summed up in the words: a little extra preliminary biology to start with, and an increased knowledge of the specialities, and a higher general standard of clinical work at the final examination

Of the four examinations which are now demanded of the student at the Conjoint Board for England, the first will consist of four subjects, each of which may be passed separately, viz., chemistry and physics, practical pharmacy, biology, and elementary anatomy. In other words, elementary physiology has given place to biology, and practical pharmacy, which previously might be taken as part of the first or second examination, may, under the new scheme, form part of the third as well. The first three of these subjects may be studied though not passed before registration. Little is to be gained by adopting such a course, as the five years which must elapse between registration and the final examination will not be thereby curtailed. (BMF 1892;ii:560) 